\title{
Analysis of Plasma Homocysteine Levels in Patients with Unstable Angina
}

\author{
José Roberto Tavares, Vânia D'Almeida, Daniela C. Diniz, Carolina A. Terzi, Edison N. Cruz, \\ Edson Stefanini, Adagmar Andriollo, Angelo A.V. de Paola, Antonio C. Carvalho \\ São Paulo, SP - Brazil
}

\begin{abstract}
Objective - To determine the prevalence of hyperhomocystinemia in patients with acute ischemic syndrome of the unstable angina type.

Methods - We prospectively studied 46 patients (24 females) with unstable angina and 46 control patients (19 males), paired by sex and age, blinded to the laboratory data. Details of diets, smoking habits, medication used, body mass index, and the presence of hypertension and diabetes were recorded, as were plasma lipid and glucose levels, C-reactive protein, and lipoperoxidation in all participants. Patients with renal disease were excluded. Plasma homocysteine was estimated using high-pressure liquid chromatography.
\end{abstract}

Results - Plasma homocysteine levels were significantly higher in the group of patients with unstable angina $(12.7 \pm 6.7 \mu \mathrm{mol} / \mathrm{L})$ than in the control group $(8.7 \pm 4.4 \mu \mathrm{mol} / \mathrm{L})(p<0.05)$. Among males, homocystinemia was higher in the group with unstable angina than in the control group, but this difference was not statistically significant (14.1 $\pm 5.9 \mathrm{\mu mol} / \mathrm{L}$ versus $11.9 \pm 4.2 \mu \mathrm{mol} / \mathrm{L})$. Amongfemales, however, a statistically significant difference was observed between the 2 groups: $11.0 \pm 7.4 \mu \mathrm{mol} / \mathrm{L}$ versus $6.4 \pm 2.9 \mu \mathrm{mol} / \mathrm{L}(p<0.05)$ in the unstable angina and control groups, respectively. Approximately $24 \%$ of the patients had unstable angina at homocysteine levels above $15 \mathrm{\mu mol} / \mathrm{L}$.

Conclusion - High homocysteine levels seem to be a relevant prevalent factor in the population with unstable angina, particularly among females.

Keywords: acute ischemic syndrome, unstable angina, homocysteine

Universidade Federal de São Paulo - Escola Paulista de Medicina Mailing address: José Roberto Tavares - Av. Jandira, 731/23 - 04080-004 São Paulo, SP, Brazil - E-mail: jrtavares@directnet.com.br English version by Stela Maris C. e Gandour
The clinical risk factors for coronary artery disease include hypercholesterolemia, hypertension, smoking, and diabetes mellitus. An increase in the plasma concentration of homocysteine has also been associated with early coronary artery disease ${ }^{1-8}$. The relation between hyperhomocystinemia and coronary artery disease was due to the discovery of the deficiency of the cystathionine beta-synthase enzyme. This enzyme is deficient in homocystinuria, a rare genetic disorder characterized by high concentrations of homocysteine, in which the patients usually develop early occlusive arterial disease ${ }^{9}$. Alterations in the methylenetetrahydrofolate reductase enzyme, which is necessary for the metabolism of homocysteine, may also play a significant role in hyperhomocystinemia. Since the identification of homocysteine as a risk factor for the development of atherosclerosis in the $1960 \mathrm{~s}^{10}$, the current research has focused on determining the actual importance of and the role played by homocysteine as a risk factor for vascular diseases. However, no similar study has ever been published in Brazil.

High plasma homocysteine levels are associated with coronary artery disease, but the precise level associated with an increased risk is yet controversial. Our study aimed at analyzing plasma homocysteine levels that are associated with the risk of coronary artery disease in our environment, particularly in the acute ischemic syndromes of the unstable angina type.

\section{Methods}

We studied 92 patients divided into 2 groups as follows: 46 patients ( 24 females) with unstable angina diagnosed at the time of recruitment (unstable angina group) and 46 patients (19 males) with no coronary artery disease (control group). The patients were consecutively and prospectively recruited at the coronary unit of the Hospital São Paulo of the Escola Paulista de Medicina of the UNIFESP.

All patients in the unstable angina group met the clinical criteria for the diagnosis of unstable angina and had 
electrocardiographic alterations compatible with that diagnosis. These patients were stratified for the risk of death or infarction, or both, into low, moderate, and high risk, according to Braunwald's criteria ${ }^{11}$, as follows: low risk, $26.1 \%$; moderate risk, $63.0 \%$; and high risk, $10.9 \%$. In the unstable angina group, we observed the presence of depression of the ST segment in $12(26.1 \%)$ patients, elevation of the ST segment in $5(10.9 \%)$ patients, inverted $\mathrm{T}$ in $22(47.8 \%)$ patients, and no alteration in the electrocardiogram in 7 $(15.2 \%)$ patients. The use of medication is shown in table I.

At the end of hospitalization, all patients remained with the diagnosis of unstable angina.

The 46 patients (19 males) with no cardiovascular disease were randomly recruited in the outpatient clinics of other specialties with no disease considered risky. These patients were paired by sex and age.

All participants completed a questionnaire about their habits, diets, use of medication, presence of risk factors, antecedents, and procedures related to coronary disease. They also underwent blood withdrawal after formal written consent. The protocol had been previously approved by the Committee on Ethics and Research at our institution. We excluded patients with renal diseases using certain medications, such as phenytoin, carbamazepine, and methotrexate, which could interfere with the plasma homocysteine levels.

In all patients, weight and height were obtained, and the body mass index was determined according to the WHO classification of obesity.

Total plasma homocysteine levels were determined according to the methodology of Pfwiffer et al ${ }^{12}$, which combines all the conditions for a good analysis (sensitivity, specificity, and reproducibility). This is high-pressure liquid chromatography with fluorometric detection and isocratic elution, using a specific substrate of the thiol group, 7-fluoro-2,1,3-benzoxadiazole-4-sulfonate(SBD-F).

To measure plasma lipoperoxidation, we used the technique of Ohkawa et al ${ }^{13}$ based on the detection of substances reactive to thiobarbituric acid (TBARs), mainly malondialdehyde, which appears after lipoperoxidation of the cellular membrane. The presence of this substance is indicated by a pinkish color, and it is measured with a spectrophotometer at $535 \mathrm{~nm}$.

Measurement of C-reactive protein was determined through an immunochemical reaction that occurs between that protein and antiprotein $\mathrm{C}$ antibodies fixed to latex particles. When C-reactive protein levels are above $8 \mathrm{mg} / \mathrm{L}$, visi-

\begin{tabular}{|c|c|c|}
\hline Medication & Number of patients & $\%$ \\
\hline Nitrates & 39 & 84.8 \\
\hline ACE inhibitors & 21 & 45.6 \\
\hline Acetylsalicylic acid & 40 & 86.9 \\
\hline Diuretics & 10 & 21.7 \\
\hline Beta-blockers & 32 & 69.6 \\
\hline
\end{tabular}

ble agglutination of the latex particles occurs (RapiTex CRP, Behring Diagnostics). This technique provides a qualitative or semiquantitative determination. Another methodology used that provided a precise determination of the C-reactive protein levels was nephelometry (NA Latex CRP Reagent, Behring Diagnostics), in which case the results were also expressed in $\mathrm{mg} / \mathrm{L}$, and values up to $8 \mathrm{mg} / \mathrm{L}$ were considered normal.

Other measurements, such as glucose, triglycerides, total cholesterol, and fractions were quantified using the standard methodology of the clinical laboratory of the Hospital São Paulo.

According to the established diagnosis of unstable angina and to control patients who supposedly had no coronary artery disease, we analyzed differences in age, sex, race, and body mass index (tab. II).

We also assessed the presence of risk factors, previous cardiovascular history, percutaneous interventional procedures related to coronary artery disease, alterations in the T wave and in the ST segment, and also the presence of previous stroke (tab. II). We considered as diabetic, hypertensive, and dyslipidemic, the patient being treated for any of these conditions or who reported a previous diagnosis of any of these conditions established by a physician. A smoker was defined as someone who had been regularly smoking up to 5 cigarettes a day for at least 1 year, or someone who had been smoking during the year prior to the study; a nonsmoker was someone who had never smoked or who had not smoked for more than 10 years; and an ex-smoker was someone who had not smoked in the year prior to the study, but had done it before.

Statistical analysis - Discrete variables were compared using the test of difference between the proportions, and continuous variables were compared using the test of difference between the means (Student $t$ test). For both cases, the critical value of significance level of $p<0.05$ was adopted. The analysis of the mean homocysteine levels,

\begin{tabular}{|c|c|c|c|}
\hline & $\begin{array}{l}\text { Unstable angina } \\
\qquad(\mathrm{n}=46)\end{array}$ & $\begin{array}{c}\text { Controls } \\
(n=46)\end{array}$ & $\mathrm{P}$ \\
\hline Age (years) & $57.6 \pm 12$ & $55.7 \pm 11.8$ & 0.46 \\
\hline $\operatorname{Sex}($ male $) \%$ & 52.1 & 41.3 & 0.67 \\
\hline Caucasian $(\%)$ & 58.7 & 60.5 & 0.99 \\
\hline $\mathrm{BMI}\left(\mathrm{kg} / \mathrm{m}^{2}\right)$ & $27.8 \pm 7.2$ & $27.9 \pm 5.7$ & 0.94 \\
\hline Hypertension (\%) & 69.6 & 17.4 & $<0.001$ \\
\hline Diabetes $(\%)$ & 28.2 & 8.7 & 0.04 \\
\hline Dyslipidemia (\%) & 23.9 & 6.5 & 0.03 \\
\hline Smoking $(\%)$ & 19.5 & 17.3 & 0.98 \\
\hline Previous angina (\%) & 34.8 & - & - \\
\hline Previous myocardial infarction $(\%$ & 41.3 & - & - \\
\hline Typical angina (\%) & 80.4 & - & - \\
\hline Previous stroke $(\%)$ & 8.7 & - & - \\
\hline ECG alterations $(\%)$ & 84.7 & - & - \\
\hline Previous angioplasty (\%) & 8.7 & - & - \\
\hline Stent placement $(\%)$ & 2.2 & - & - \\
\hline
\end{tabular}


despite the sample size, followed a normal distribution curve according to the Kolmogorov-Smirnov test that assesses normality $(\mathrm{p}=0.17)$.

\section{Results}

Table III shows the mean values found in the laboratory tests. The mean values of total cholesterol, LDL-cholesterol, lipoperoxidation, and triglycerides were similar in both groups. No biochemical examination showed any difference between the proportion of altered values in the 2 groups. The mean glycemia and HDL-cholesterol values, however, were different in both groups. To compare the total plasma homocysteine levels, the means of the 2 groups \pm standard deviation were considered, and the values of plasma concentration were expressed in micromoles per liter $(\mu \mathrm{mol} / \mathrm{L})$. The mean total plasma homocysteine levels were significantly more elevated in the unstable angina group $(p=0.001)$.

Measuring the C-reactive protein levels may have practical clinical significance in managing patients hospitalized with acute ischemic syndromes, but this was not our objective. In the unstable angina group, $43.5 \%$ of the patients had normal C-reactive protein levels $(<8 \mathrm{mg} / \mathrm{L})$, which was found in $65.2 \%$ of the patients in the control group $(\mathrm{p}=0.07)$. However, more elevated levels $(>8 \mathrm{mg} / \mathrm{L})$ were found in $56.5 \%$ of the patients in the unstable angina group and in $34.8 \%$ of the patients in the control group $(\mathrm{p}=0.056)$. Even though the means for C-reactive protein were similar in both groups, when we classified the patients according to their levels of C-reactive protein as individuals with normal $(<8 \mathrm{mg} / \mathrm{L})$ and elevated $(>8 \mathrm{mg} / \mathrm{L})$ values, we observed a tendency towards more elevated levels in the unstable angina group (fig. 1). These results show that more elevated levels of C-reactive protein were found among the patients with higher homocysteine levels, both for the unstable angina and control groups.

The homocysteine values (mean \pm standard deviation) found in the total sample divided by the increased or normal C-reactive protein levels were compared using the 1way ANOVA and followed by the Duncan test. This showed that C-reactive protein levels do not relate to homocysteine levels and unstable angina, but, when increased, these levels relate to higher homocysteine values, regardless of the group the individuals belong to. In the unstable angina group with elevated C-reactive protein levels, we

\begin{tabular}{|lccc|}
\hline \multicolumn{4}{|c|}{ Table III - Biochemical analyses } \\
\hline & $\begin{array}{c}\text { Unstable angina } \\
(\mathrm{n}=46)\end{array}$ & $\begin{array}{c}\text { Controls } \\
(\mathrm{n}=46)\end{array}$ & $\mathrm{P}$ \\
& & $101.6 \pm 15$ & $<0.001$ \\
\hline Glycemia (mg/dL) & $144.5 \pm 75.1$ & $12.7 \pm 45.3$ & 0.85 \\
Total cholesterol (mg/dL) & $214.4 \pm 40.5$ & 212.3 & 0.003 \\
HDL-cholesterol (mg/dL) & $40 \pm 16.1$ & $49.5 \pm 12.3$ & 0.26 \\
LDL-cholesterol (mg/dL) & $133.7 \pm 42.4$ & $123.9 \pm 38$ & 0.62 \\
Triglycerides (mg/dL) & $190.9 \pm 101.3$ & $180.6 \pm 95$ & 0.67 \\
Lipoperoxidation (nmols/mL) & $1.8 \pm 1$ & $1.7 \pm 1.5$ & $0.001 *$ \\
Homocysteinemia (mmol/L) & $12.7 \pm 6.7$ & $8.7 \pm 4.4$ & \\
\hline
\end{tabular}

Plasma homocysteine levels in patients with unstable angina

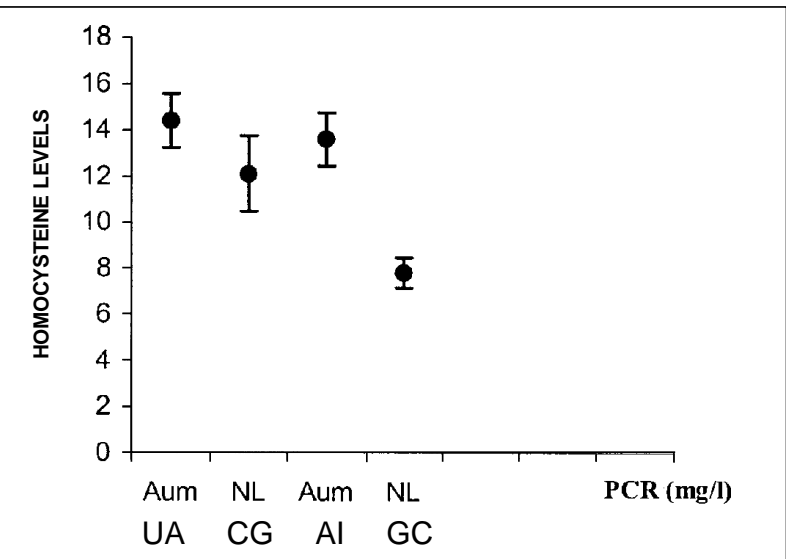

Fig. 1 - * Homocysteine levels compared with C-reactive protein levels; * standard error of the mean; elevated levels: $>8 \mathrm{mg} / \mathrm{L}$; normal levels: $<8 \mathrm{mg} / \mathrm{L}$; UA- unstable angina; CG - control group.

found mean homocysteine levels of $14.4 \pm 5.9 \mu \mathrm{mol} / \mathrm{L}$, and, in the control group, we found mean homocysteine levels of $13.6 \pm 4.6 \mu \mathrm{mol} / \mathrm{L}$. On the other hand, fornormalC-reactive protein levels, we found mean homocysteine levels of $12.1 \pm 7.3$ $\mu \mathrm{mol} / \mathrm{L}$ in the unstable angina group, and $7.8 \pm 3.5 \mu \mathrm{mol} / \mathrm{l}$ in the control group (fig. 1).

Analyzing the mean plasma homocysteine levels, when we compare the 2 groups (patients and controls) paired by sex, we observed a higher and more significant elevation among the females of the unstable angina subgroup $(\mathrm{p}=0.005)($ tab. IV $)$.

In the international literature, normal fasting homocystinemia ranges from 5 to $15 \mu \mathrm{mol} / \mathrm{L}$. Concentrations between 16 and $30 \mu \mathrm{mol} / \mathrm{L}$ are considered slightly increased, between 31 and $100 \mu \mathrm{mol} / \mathrm{L}$ are considered moderately increased, and above $100 \mu \mathrm{mol} / \mathrm{L}$ are considered markedly increased. In our study, analyzing the plasma homocysteine levels above $15 \mu \mathrm{mol} / \mathrm{L}$ in both groups again paired by sex, we observed a significant difference in the female unstable angina subgroup as compared with the female control subgroup. This fact was not observed for the male sex (tab. V). Analyzing the sample with no sex distinction, no significant difference was observed in the 2 groups (tab. V).

Considering the male sex, the mean plasma homocysteine levels in the unstable angina group as compared with those in the control group were not significantly higher $(p=0.52)$. It is worth noting that, in this small sample, the mean homocysteine levels in the control group were lower. In the unstable angina group, approximately $24 \%$ of the patients had undoubtedly increased plasma homocysteine levels, which occurred in only $8.6 \%$ of the control group.

\begin{tabular}{|c|c|c|c|}
\hline \multicolumn{4}{|c|}{ Table IV - Homocysteine level according to sex ( $\mathrm{mmol} / \mathrm{L})$} \\
\hline & $\begin{array}{l}\text { Unstable angina } \\
\qquad(\mathrm{n}=46)\end{array}$ & $\begin{array}{l}\text { Controls } \\
(\mathrm{n}=46)\end{array}$ & $\mathrm{P}$ \\
\hline \multicolumn{4}{|l|}{ Sex } \\
\hline Male & $14.3 \pm 5.8 \quad(24 p)$ & $11.6 \pm 4.2(19 \mathrm{p})$ & 0.096 \\
\hline Female & $10.9 \pm 7.2 \quad(22 p)$ & $6.4 \pm 2.9 \quad(27 p)$ & $0.005^{*}$ \\
\hline
\end{tabular}




\begin{tabular}{|lccc|}
\hline \multicolumn{4}{|c|}{ Table V - Plasma homocysteine levels above $\mathbf{1 5} \mathbf{~ m m o l} / \mathbf{L}$} \\
\hline Sex & $\begin{array}{c}\text { Unstable angina } \\
(\mathrm{n}=46)\end{array}$ & $\begin{array}{c}\text { Control } \\
(\mathrm{n}=46)\end{array}$ & $\mathrm{P}$ \\
\hline Male & $29.2 \%(07)^{*}$ & $21 \%(04)^{*}$ & 0,52 \\
Female & $18.2 \%(04)^{*}$ & - & - \\
Total (male + female) & $23.9 \%(11)^{*}$ & $8.6 \%(04)^{*}$ & 0.097 \\
\hline * Number of patients with homocysteine levels above $15 \mathrm{mmol} / \mathrm{L}$ \\
\hline
\end{tabular}

In an attempt to answer the question whether homocysteine is an independent risk factor for unstable angina, the logistic regression analysis was performed. When compared with other risk factors, such as diabetes, dyslipidemia, smoking, hypertension, sex, and age, homocysteine proved to be an independent risk factor $(\mathrm{p}<0.0025$, with a confidence interval of $95 \%$ ) in patients with unstable angina.

\section{Discussion}

Measuring C-reactive protein levels may have practical clinical significance in managing hospitalized patients with acute ischemic syndromes, but this was not our objective. Even though the means for C-reactive protein were similar in the 2 groups, when the groups were subdivided into individuals with normal $(<8 \mathrm{mg} / \mathrm{L})$ and high $(>8 \mathrm{mg} / \mathrm{L})$ levels, a tendency towards a difference was observed in the unstable angina group (fig. 1). It is worth emphasizing that the highest levels of C-reactive protein were found in individuals with the highest homocysteine levels both for the unstable angina and control groups.

Some studies have shown that C-reactive protein levels measured on hospital admission in patients suspected of having ischemic heart disease identified patients at high risk for acute myocardial infarction and unstable angina.

Mach et al ${ }^{14}$ reported that C-reactive protein levels measured on hospital admission in patients suspected of having ischemic heart disease may be a marker of acute coronary syndromes and may be very useful in identifying patients at high risk for developing myocardial infarction.

In another study, Luigi et al ${ }^{15}$ reported that, in unstable angina, $\mathrm{C}$-reactive protein may remain elevated for 3 or more months after the disease symptoms and may be associated with recurring instability.

Ernesto et al ${ }^{16}$ concluded that $\mathrm{C}$-reactive protein is a strong independent marker of an increase in risk in 90 days. Comparing C-reactive protein on admission and $\mathrm{C}$-reactive protein on hospital discharge, the latter may be very useful for risk stratification.

An elevated homocysteine level is 1 of many risk factors identified for vascular diseases. Homocysteine is an amino acid that contains a sulfur radical and is an intermediate product of the metabolism of cysteine from methionine (an essential amino acid found in the dietary proteins).

Intriguing observations suggest that homocysteine plays a significant role in the development of vascular disea- ses. Individuals with homocystinuria ${ }^{17}$, a recessive autosomal disorder, have severe hyperhomocystinemia, early atherosclerosis, and thromboembolic complications ${ }^{18}$. Homocysteine may promote the oxidation of low-density lipoproteins, proliferation of smooth muscle cells, activation of platelets and of the coagulation factors, and endothelial dysfunction ${ }^{19}$.

Determining the normal homocysteine levels is difficult because of its continuous biochemical variability. The prevalence of homocystinemia in the general population ranges from $5 \%$ to $10 \%$, approximately $15 \mathrm{mmol} / \mathrm{L}$ in the $90^{\text {th }}$ to the $95^{\text {th }}$ percentile ${ }^{20}$. However, it seems to be higher in the elderly population $(30 \% \text { to } 40 \%)^{21}$. If these results are correct, approximately $10 \%$ of coronary artery disease events may be attributed to elevated homocysteine levels ${ }^{22}$.

Elevated homocysteine levels are associated with sex (higher levels in males), postmenopausal status in females, age increase, nutritional aspects, plasma levels of vitamins $\mathrm{B}_{6}, \mathrm{~B}_{12}$, and folate, renal function, genetic predisposition, and thyroid function ${ }^{20}$. Some medications, such as niacin, methotrexate, and phenytoin, may also increase homocysteine levels ${ }^{20-23}$. Ethnic differences have been reported to interfere with the homocysteine levels, which are lower in black individuals as compared with Caucasian and Asian individuals ${ }^{24-33}$.

For high-risk patients, some authors recommend the $10-\mu \mathrm{mol} / \mathrm{L}$ level as a therapeutic target ${ }^{25,26}$. Approximately 30 studies have compared the homocysteine levels of patients with coronary artery disease and those of control groups with no disease ${ }^{27,28}$. Patients with coronary artery disease had significantly higher fasting plasma homocysteine levels in 22 out of 27 studies ${ }^{29,30}$ with a risk ratio of 1.2 to 10.9 after adjusting for other risk factors. Two metaanalyses of retrospective studies confirm these findings ${ }^{22-31}$. Homocysteine may be considered a risk factor, as may smoking ${ }^{32,33}$, hypertension ${ }^{32-34}$, dyslipidemia ${ }^{31,35,36}$, and hyperglycemia ${ }^{37}$; it seems, however, to be an independent factor ${ }^{38,39}$.

In 1969 , McCully ${ }^{10}$ suggested that homocysteine had a direct toxic effect on cultures of endothelial cells and correlated the vascular disease with elevated concentrations of homocysteine. In another study, that author ${ }^{40}$ showed in an experimental model of atherogenesis that the elevated concentration of plasma homocysteine, even in the presence of low-lipid diets, related to intimal lesion. Epidemiological evidence has shown that the presence of moderate hyperhomocystinemia is an independent risk factor for atherosclerosis in the coronary, cerebral, and peripheral vascular circulations ${ }^{6,41}$.

In a recent study, Evans et al ${ }^{42}$ did not show the relation between plasma homocysteine levels, nonfatal myocardial infarction, and coronary artery disease. In that study, the mean homocysteine levels in the patients with nonfatal myocardial infarction $(\mathrm{n}=93)$ and in those with death due to coronary artery disease $(n=47)$ were $12.6 \mu \mathrm{mol} / \mathrm{L}$ and 12.8 $\mu \mathrm{mol} / \mathrm{L}$, respectively. In the control group, the homocysteine levels in individuals with nonfatal infarction and in those with death due to coronary artery disease were 13.1 
$\mu \mathrm{mol} / \mathrm{L}(\mathrm{n}=136)$ and $12.7 \mu \mathrm{mol} / \mathrm{L}(\mathrm{n}=286)$, respectively. These data do not support the hypothesis that high plasma homocysteine levels increase the risk of coronary artery disease, suggesting another possible mechanism in which homocysteine may be a predictor in a later stage of the disease. The findings of that study are similar to those of other longitudinal studies investigating this association. Unlike retrospective studies, longitudinal studies have shown that plasma homocysteine levels in patients with myocardial infarction and coronary artery disease are similar to those in the control group.

Folsom et al ${ }^{43}$ concluded that alterations in homocysteine levels were positively associated with age, race, and incidence of coronary artery disease in females, but not in males. However, after adjusting for other risk factors for coronary artery disease, no independent association with coronary artery disease was observed in the same population. Even though some cross-sectional studies typically measured homocysteine in some cases at least 3 months after an acute event of coronary artery disease, homocysteine may have remained as a consequence of the disease.

A recent study by Peter et al $^{44}$, the first to analyze homocysteine levels in patients with unstable angina, showed the relation between plasma homocysteine levels at 28 days and at 2.5 years after hospital admission as a prognosis for nonfatal coronary disease and death in acute ischemic syndromes. The authors analyzed the relation of the homocysteine quintiles for fatal and nonfatal events of early ( 28 days) and late (29 days to 2.5 years) coronary artery disease in 204 patients with unstable angina and 236 with acute myocardial infarction. The final events studied were cardiac death $(n=67)$ and myocardial reinfarction $(n=30)$. After logistic regression to estimate the relation between homocysteine and coronary events, the authors concluded that the rate of events in the first 28 days ( 22 cardiac deaths and 5 nonfatal infarctions) did not relate to homocysteine levels on hospital admission. In 203 patients with unstable angina and 214 patients who survived myocardial infarction, an apparent effect was observed in the long run. Patients in the 2 upper quintiles (homocystinemia $>12.2 \mu \mathrm{mol} / \mathrm{L}$ ) had a 2.6fold increase in the risk of cardiac events $(95 \%$ confidence interval, 1.5 to $4.3, \mathrm{p}<0.001)$. In conclusion, an elevated homocysteine level on hospital admission is a strong predictor of late cardiac events in acute ischemic syndrome.
The American Heart Association guidelines consider it reasonable to select for treatment patients with elevated homocysteine levels who have a high risk for vascular disease, such as those with renal failure, or those with a familial or personal history of early atherosclerosis. Several specialists in this area agree ${ }^{45,46}$ and suggest a reduction in the fasting total homocysteine levels to below $10 \mu \mathrm{mol} / \mathrm{L}^{45}$.

In our study, more elevated mean homocysteine levels were strongly associated with the presence of unstable angina, particularly in the female sex. The association of diabetes and dyslipidemia was higher in the group with unstable angina. This is an important study because of the epidemiological connotation of coronary artery disease. The costbenefit relation of the treatment for hyperhomocystinemia, as compared with that of the treatment for other risk factors, is good because it comprises the use of B complex vitamins and folic acid.

Our study points to the need for wider studies to assess this significant risk factor and also to clarify the role played by homocysteine, as well as its relation to other risk factors for coronary artery disease.

Even considering the elevated homocysteine levels reported in the literature ( $>15 \mu \mathrm{mol} / \mathrm{L}$ ) for cut values, we found $24 \%$ of our population with unstable angina with values above that level.

As limitations of our study, we can cite the higher number of dyslipemic and diabetic patients in the unstable angina group, and the lack of cardiac catheterization in all patients. Larger samples may be required to exclude variables with bias potential. This is an initial study that may be expanded to encompass a future analysis of young patients with early coronary artery disease and elderly patients.

Briefly, we should be aware that hyperhomocystinemia is an independent risk factor for coronary artery disease, and that, in addition, it may act synergistically with other properly defined risk factors, such as diabetes, hypercholesterolemia, and hypertension, to induce endothelial dysfunction, early atherosclerosis, and thrombosis.

\section{Acknowledgments}

This study was funded by the FAPESP (process 97/ 1870-4).

\section{References}

1. Wilcken DEL, Wilken B. The pathogenesis of coronary artery disease: a possible role for methionine metabolism. J Clin Invest 1976; 57: 1079-82.

2. Kang SS, Wong PWK, Cook HY, et al. Protein-bound homocysteine a possible risk factor for coronary artery disease. J Clin Invest 1986; 77: 1482-6.

3. Clarke R, Daly L, Robinson K, et al. Hyperhomocysteinemia: an independent risk factor for vascular disease. N Engl J Med 1991; 324: 1149-55.

4. Genest JJ Jr, McNamara Jr, Salem DN, et al. Plasma homocysteine levels in men with premature coronary artery disease. J Am Coll Cardiol 1990; 16: 1114-9.

5. Malinow MR, Kang SS, Taylor LM, etal. Prevalence of hiperhomocysteinemia in patients with peripheral arterial occlusive disease. Circulation. 1998: 79: 1180-8.
6. Stampfer MJ, Malinow MR, Willet $\mathrm{W}$ C, et al. A prospective study of plasma homocysteine and risk of myocardial infarction in U.S. physicians. JAMA 1992; 286:877-81.

7. Grahan IM. Homocysteinaemia and vascular disease. I Vuylsteek K, Hallen M, eds. Commission of the European Community. Ios Press; 1994: 332-53.

8. Wu LL, Wu J, Hunt SC, et al. Plasma homocysteine as a risk factor for early familial coronary artery disease. Cli Chem 1994; 40: 552-61.

9. Mudd SH, Levy HL, Skouby F. Disorders of transsulfuration. In: Scriver CR, Beaudet AL, Sly WS, Valle D, eds. The Metabolic Basis of Inherited Disease. New York: McGraw-Hill; 1989: 693-734. 
10. McKully KS. Vascular pathology of homocysteinemia: implications for the pathogenesis of arteriosclerosis. Am J Pathol 1969; 56: 11-28.

11. Braunwald E, Robert HJ, Daniel BM, et al. Diagnosing and managing unstable angina. Circulation 1994; 90: 613-22.

12. Pfweiffer CM, HuffDL, Gunter EW. Rapid and accurate HPLC assay for plasma to homocysteine and cysteine in a Clinical Laboratory Setting. Clin Chem 1999; 45: $290-92$.

13. Ohkawa H, Ohishi N, Yagi K. Assay for lipid peroxides in animal tissues by thiobabituric acid reaction. Anal Biochem 1979; 95: 351-8.

14. Mach F, Lovis C, GaspozP-F, et al. C-reactive protein as a marker for acute coronary syndromes. Eur Heart J 1997; 18: 1879-902.

15. Luigi MB, Giovanna L, Rita L, et al. Elevated levels of C-Reactive Protein at a discharge in patients with unstable angina predict recurrent instability. Circulation 1999; 99: 855-60.

16. Ernesto RF, Carlos PB, Rodolfo P, et al. Idependent prognostic value of elevated C-Reactive Protein in unstable angina. Circulation 1999; 100: 1958-63.

17. Skovby F. Inborn error of metabolism causing homocysteinemia and related vascular involvement. Haemostasis 1989; 19: 4-9.

18. Mudd SH, Skovby F, Levy HL, et al. The natural history of homocystinuria due to cystationine b-synthase deficiency. Am J Hum Genet 1985; 37: 1-31.

19. Moghadasian MH, McManus BM, Frohlich JJ, et al. Homocysteine and coronary artery disease. Clinical evidence and genetic and metabolic background. Arch Intern Med 1997; 157: 2299-308.

20. Refusun H, Ueland PM, Nygard O, et al. Homocysteine and cardiovascular disease. Annu Rev Med 1998; 49: 31-62.

21. Selhub J, Jacques PF, Wilson PWF, et al. Vitamin status and intake as primary determinants of homocysteinemia in an elderly population. JAMA 1993; 270: 2693-8.

22. Boushey CJ, Beresford SAA, Omenn GS, et al. A quantitative assessment of plasma homocysteine as a risk factor for vascular disease. Probable benefits of increasing folic acid intakes. JAMA 1995; 274: 1049-57.

23. De Largeril M, Salen P, Paillard F, et al. Lipid lowering drugs and homocysteine. Lancet 1999; 353: 209-10.

24. Ubbink JB, Vermaan WJH, Deport R, et al. Effective homocysteine metabolism may protect South African black against coronary heart disease. An J Clin Nut 1995; 62: 802-8.

25. Malinow MR, Boston AG, Kraurs RM, et al. Homocysteine diet, and cardiovascular disease: a statement for healthcare professionals from the Nutrition Committee. American Heart Association. Circulation 1999; 99: 178-82.

26. Genest J Jr. Emerging risk factors associated with cardiovascular diseases. Canadian Cardiovascular Society 1998. Consensus Conference on the Prevention of Cardiovascular diseases. Can J Cardiol 1999, 15(suppl G): 73G-6G.

27. von Eckardstein A, Malinow MR, Upson B, et al. Effects of age, lipoproteins, and hemostatic parameters on the role of homocysteinemia as a cardiovascular risk factor in men. Arterioscler Thromb 1994; 14: 460-4.

28. Kang SS, Passen EL, Ruggie N, et al. Thermolabile defect of methylenetetrahydrofolate reductase in coronary artery disease. Circulation 1993; 88: 1463-9.

29. Olszewski AI, Szostak WB. Homocysteine content of plasma proteins in ischemic heart disease. Atherosclerosis 1998; 69: 109-13.
30. Israelsson B, Brattström LE, Hultheberg BL. Homocysteine and myocardial infarction. Atherosclerosis 1998; 71: 227-33.

31. Wald NJ, Watt HC, Law MR, et al. Homocysteine and ischemic heart disease. Results of a prospective study with implications regarding prevention. Arch Intern Med 1998; 158: 862-7.

32. Graham IM, Daly LE, Refsum HM, et al. Plasma homocysteine as a risk factor for vascular disease. The European Concerted Action Project. JAMA 1997; 277 1775-81.

33. Lolin YI, Sanderson JE, Cheng SK, et al. Hyperhomocystanaemia and premature coronary artery disease in the Chinese. Heart 1996; 76: 117-22.

34. MontalescotG, Ankri A, Chadefaux-Vekemans B, etal. Plasma homocysteine and the extent of atherosclerosis in patients with coronary artery disease. Int J Cardio 1997; 60: 295-300

35. Wu LL, Wu J, Hunt SC, et al. Plasma homocysteine as a risk factor for early familial coronary artery disease. Clin Chem 1994; 40: 552-61.

36. Loehrer FMT, Angst CP, Haefeli WE, et al. Low whole blood S-adenosylmethionine and correlation between 5-methyltetrahydrofolate and homocysteine in coronary artery disease. Arterioscl Thromb Vasc Biol 1996; 16: 727-33.

37. Hoogeveen EK, Kostense PJ, Beks PJ, et al. Hyperhomocysteinemia is associated with an increased risk of cardiovascular disease, especyally in non-insulindependent diabetes mellitus: a population based study. Arterioscler Thromb Vasc Biol 1998; 18: 133-8.

38. Dalery K, Lussier-Cacan S, Selhub J, et al. Homocysteine and coronary artery disease in French Canadian subjects: relation with vitamina B 12, B6, pyridoxa phosphate, and folate. Am J Cardiol 1995; 75: 1107-11

39. Verhoef P, Kok FJ, Kruyssen DACM, et al. Plasma total homocysteine, B vitamins, and risk of coronary atherosclerosis. Arterioscler Thromb Vasc Biol 1997; 17: 989-95.

40. Mc Cully KS, Olszewski AJ, Vezeridis MP, et al. Homocysteine and lipid metabolism in atherogenisis: effect of the homocysteine thiolactonyl derivates, thioretinaco and thioretinamide. Atherosclerosis 1990; 83: 197-206.

41. Kang SS, Wong PW, Malinow MR. Hyperhomocysteinemia as a risk factor for occlusive vascular disease. Ann Rev Nutr 1992; 12: 279-98.

42. Evans RW, Shaten J, Hempel JD, et al. MRFIT Research Group Homocysteine and risk of cardiovascular disease in the Multiple Risk Factor intervention Trial. Arterioscler Thromb Vac Biol 1997; 17: 1947-53.

43. Folsom AR, Nieto FJ, McGovern PG, et al. Prospective study of coronary heart disease incidence in relation to fasting total homocysteine, related genetic polymorphisms, and vitamins - The Atherosclerosis risk in communities (ARIC) Study. Circulation 1998; 98: 204-10

44. Peter JS, Mohamed K, Al-Obaidi, et al. Effect of plasma homocysteine concentration on early and late events in patients with acute coronary syndromes. Circulation 2000; 102: 605-10.

45. Omenn GS, Beresford SAA, Motulsky AG. Preventing coronary heart disease: B vitamins and homocysteine. Circulation 1998; 97: 421-4.

46. Genest J Jr. Hyperhomcysteinemia - determining factors and treatment. Can J Cardiol 1999; 15(suppl B): 35B-38B. 